Nastia Degiuli

Andrea Farkas

Ivana Martić

Ivan Zeman

Valerio Ruggiero

Vedran Vasiljević

http://dx.doi.org/10.21278/brod72305 $\quad$ ISSN 0007-215X

eISSN 1845-5859

\title{
NUMERICAL AND EXPERIMENTAL ASSESSMENT OF THE TOTAL RESISTANCE OF A YACHT
}

UDC 629.5.015.2:629.5.018.71:629.5.024.32:629.525

Original scientific paper

\begin{abstract}
Summary
One of the main goals of the ship design process is the reduction of the total resistance, which is nowadays even more highlighted due to increasingly stringent rules related to ship energy efficiency. In this paper, the investigation of the impact of the bow on the total resistance of a yacht is carried out for three models by towing tank tests and numerical simulations. The verification and validation studies are performed, and satisfactory agreement is achieved. Also, a comparison of three turbulence models for the prediction of the total resistance of a yacht is made. The flow around the models of the yacht is analysed and it is demonstrated that bulbous bow causes the reduction of wave elevations. Experimental and numerical results indicate that the decrease in the total resistance due to bulbous bow can be up to $7 \%$. Finally, the applicability of CFD within the ship design process is presented.
\end{abstract}

Key words: $\quad$ yacht; bulbous bow; CFD; towing tank experiment; total resistance

\section{Introduction}

Usually, naval architects have at their disposal parent hull forms to which they apply certain adjustments to obtain a new hull form with the desired characteristics, based on the appearance and hydrostatic and hydrodynamic performance. The procedure is repeated until the design and hydrostatic and hydrodynamic performance requirements are met. This is the method of trial and error and depends largely on the experience of naval architect. In the ship design process, naval architects must conduct a series of numerical analysis in terms of hydrostatics and hydrodynamics to determine whether the hull form meets the design requirements before the final selection of a design. Hydrodynamic performance of a ship encompasses calm water resistance, seakeeping, and manoeuvrability, and Computational Fluid Dynamics (CFD) is commonly used tool for its determination [1]. Additional important goal of improving the ship hydrodynamic characteristics is related with the ship energy efficiency. Namely, there are three main technical measures to reduce greenhouse gas (GHG) emissions caused by shipping: reduction of ship resistance; improvement of propulsion 
efficiency and power generation efficiency [2]. Nowadays the determination of the total resistance is performed by numerical and experimental methods. Experiments carried out in towing tanks are time consuming and expensive, therefore in the early stages of ship design CFD has become commonly used tool. This is even more highlighted if the experiments are performed for different environmental conditions and for larger models, as presented in [3].

Niklas and Pruszko [4] have analysed numerical and experimental methods for the determination of the total resistance of ship in calm water. The authors have compared the results obtained by towing tank experiments, full-scale CFD simulations, and sea trials. It has been shown that the towing tank experiments should be supported by CFD simulations in order to reduce uncertainty. Farkas et al. [5] have carried out numerical simulations of viscous flow around a tanker model to determine the total resistance. Results obtained by numerical simulations were validated against experimental results from towing tank experiments and the obtained numerical results demonstrated satisfactory agreement. Authors have also shown that a coarse mesh can provide accurate results while significantly reducing calculation time. Standard $k-\varepsilon$ (SKE) and Realizible $k-\varepsilon$ Two-Layer (RKE2L) turbulence models were used to investigate their effect on the results of numerical simulations and similar results were obtained. Ozdemir et al. [6] have carried out numerical simulations for KRISO Container Ship (KCS) with a goal to demonstrate the capability of a general-purpose CFD code. Numerical results were compared with the experimental ones and a satisfactory agreement was obtained. CFD simulations proved to be a useful tool to gain an insight into the flow both around the damaged hull and inside the flooded tanks of the damaged tanker model with a large hole in the bottom of the hull. Due to the altered flow around the hole in the bottom and inside the flooded tanks, total resistance increased for 27\% [7]. The grid sensitivity has been investigated within [8] for the same model by applying STAR-CCM+ with RKE2L turbulence model and three grid densities. Pereira et al. [9] have performed a study regarding the quantification of numerical and modelling errors for the numerical simulation of viscous flow around KVLCC2 tanker at the model and full-scale Reynolds numbers. The authors demonstrated the scale effects by presenting the obtained results for wake-fraction at propeller plane and form factor. Farkas et al. [10] have performed a numerical and experimental assessment of nominal wake for a handymax bulk carrier at full-scale. The authors investigated the influence of different turbulence models on the nominal wake field. Turbulence models that were applied are: Realizable $k-\varepsilon$ (RKE), Shear Stress Transport $k-\omega$ (SSTKO) and Reynolds Stress Model (RSM). The experimental assessment was performed by five-hole Pitot tube with a spherical head, which can measure all components of a velocity vector. Numerical results were validated against the experimental ones and it was shown that RSM turbulence model has the lowest relative deviation between numerical and experimental results. For the same handymax bulk carrier, Farkas et al. [11] have carried out a numerical and experimental assessment of resistance and propulsion characteristics. Numerical simulations of resistance, open water and self-propulsion tests for three load conditions were performed at two speeds. Towing tank experiments were performed as well, and the extrapolated results were used to validate the results obtained by numerical simulations. A comparison of the results using different turbulence models was made and satisfactory agreement with experimental results has been achieved. RSM turbulence model has proven to be the most accurate, however it required a significantly larger computational time than the other turbulence models.

The hull modification in the early phases of ship design process is frequently used to decrease the total resistance. Presently, CFD approach is successfully applied for the optimization of ship hull [12], or determination of ship hydrodynamic characteristics for inconvenient hull forms [13]. Yu and Lee [14] have carried out a series of numerical tests to derive the regression equation for the resistance estimation. The focus of this research was to 
design the optimal bulbous bow to improve the performance of medium-sized passenger ships. The hull forms are designed by varying the bulb parameters to find the influence of the shape of the bulb on the resistance. A hull form with the reduction in pressure resistance by $32 \%$ was derived as a result of the bow design for the reference ship. Huang and Yang [15] have developed a new technique based on the radial basis functions for the generation and modification of bulbous bow and integrated it into the module for hull surface representation and modification. The applicability of the integrated optimization approach was demonstrated on an example of a cargo ship optimized for reduced resistance. The obtained results were validated numerically and experimentally, and it was shown that the developed tools can be used within the simulation based design. Khan et al. [16] have proposed a new framework for the parametric design and hull modification of a yacht, which divided the hull into three regions represented separately (entrance, middle and run). It has been shown that a variety of hull shapes can be generated using the proposed design framework by applying the shape operators. Lee et al. [17] have employed CFD simulations for the investigation of the effect of sharp and blunt bow on the reduction of total resistance for bulk carriers. The authors have demonstrated that a sharp bow has lower total resistance both in calm water and in waves. Lee et al. [18] have carried out a series of experimental tests in which they have compared three different hull forms of KVLCC2: the original hull form and two modified hull forms with different bow types, one with ax-bow and the other with leadge-bow. The results pointed out that all three hull forms have similar motion responses. However, added resistance of modified hulls was lower in comparison to original hull form, wherein the leadge-bow had the lowest added resistance. Liu et al. [19] have proposed a new type of bow appendage for highspeed ships with Froude number $(F n)$ between 0.4 and 0.5 . The goal of this appendage was to decrease the wave resistance by restraining the peak of the bow wave. The authors carried out CFD simulations to determine the total resistance, as well the towing tank experiments, which demonstrated the efficiency of this bow appendage. Niklas and Pruszko [20] have investigated two types of bulbous bow: V-shaped bulbous bow and X-bow type. The original hull has a Vshaped bulbous bow, while the new hull has a X-bow type having the same displacement as the original hull. CFD simulations were carried out to determine the calm water resistance as well as the ship's seakeeping performance, and the obtained numerical results were validated against the experimental ones. Results for calm water resistance showed that the modified hull has lower total resistance. However, seakeeping analysis demonstrated that the modified hull has higher amplitude of motions, which resulted with increased accelerations. Magionesi and Mascio [21] have carried out numerical simulations and experiments in order to gain insight into the pressure fluctuations induced by the turbulent boundary layer on the bulbous bow. They concluded that the pressure fluctuations could cause noise disturbing the operation of sonar systems installed inside the bulbous bow of fast ships. Xie et al. [22] have investigated the effect of bulbous bow on the flow around the hull and slamming loads by performing experiments.

Although the bulbous bow can improve hydrodynamic characteristics of a ship, it is very important to adopt the correct design of bulbous bow [23]. Therefore, the main aim of this study is to investigate the influence of a bulbous bow on the total resistance of a yacht. The investigations are performed using both towing tank tests and numerical simulations. The additional goal of this paper is to demonstrate the applicability of CFD within the ship design process. Case study vessel is a yacht, whose original hull form does not have bulbous bow, however two types of bulbous bow were designed and fitted to the yacht. Numerical simulations are performed using software package STAR-CCM+. Furthermore, verification study is performed to determine the numerical uncertainty and the obtained results are validated with the experimental ones. Finally, the numerical results which include the wave 
elevations and hydrodynamic pressure distribution for three models of the yacht and three turbulence models are presented.

\section{Case study vessels}

Three models of the yacht with different bow types have been subject of extensive towing tank experiments [24]. The hull has been selected because it represents a typical example of large yacht hull, according to the most recent developments of the market of large yachts [25 - 27]. The original hull form has conventional bow type (Model 2508), and two hull forms have bulbous bow (Model 2508A and Model 2508B). All models are built in a scale $\lambda=12$. Main particulars of investigated yachts are given in Table 1 , where $L_{P P}$ is the length between the perpendiculars, $B_{M}$ is the moulded breadth, $T$ is the draught, $L_{W L}$ is the length of waterline, $\nabla$ is the displacement volume, $\Delta$ is the mass of displacement, $S$ is the wetted surface, and $C_{B}$ is the block coefficient. It is important to mention that by adding the bulbous bow the displacement remained the same for all three models.

Table 1 Main particulars of case study vessels [24]

\begin{tabular}{|c|c|c|c|c|c|c|}
\hline \multirow{2}{*}{ Particular } & \multicolumn{2}{|c|}{ Model 2508 } & \multicolumn{2}{c|}{ Model 2508A } & \multicolumn{2}{c|}{ Model 2508B } \\
\cline { 2 - 7 } & Yacht & Model & Yacht & Model & Yacht & Model \\
\hline$L_{P P}, \mathrm{~m}$ & 62.88 & 5.24 & 63.60 & 5.30 & 63.60 & 5.30 \\
\hline$B_{M}, \mathrm{~m}$ & 11.50 & 0.96 & 11.50 & 0.96 & 11.50 & 0.96 \\
\hline$T, \mathrm{~m}$ & 3.98 & 0.332 & 3.95 & 0.329 & 3.98 & 0.332 \\
\hline$L_{W L}, \mathrm{~m}$ & 66.47 & 5.54 & 70.53 & 5.88 & 71.03 & 5.92 \\
\hline$\nabla, \mathrm{m}^{3}$ & 1220 & 0.71 & 1220 & 0.71 & 1220 & 0.71 \\
\hline$\Delta, \mathrm{t}$ & 1252 & 0.71 & 1252 & 0.71 & 1252 & 0.71 \\
\hline$S, \mathrm{~m}^{2}$ & 837 & 5.81 & 874 & 6.07 & 837 & 5.81 \\
\hline$C_{B}$ & 0.4239 & 0.4239 & 0.4223 & 0.4223 & 0.4191 & 0.4191 \\
\hline
\end{tabular}

Within Figure 1 models of the yacht with different bow types are presented together with their appendages including shaft outlets, propeller shafts, A-brackets, rudders and four stabilization fins. Additionally, the bow contours of investigated models are shown in Figure 2 to demonstrate the difference between bow types more clearly. To enable the modification of the bow part of the yacht, a bulkhead is inserted at frame 46 and two versions of bulbous bows are prefabricated [24]. 

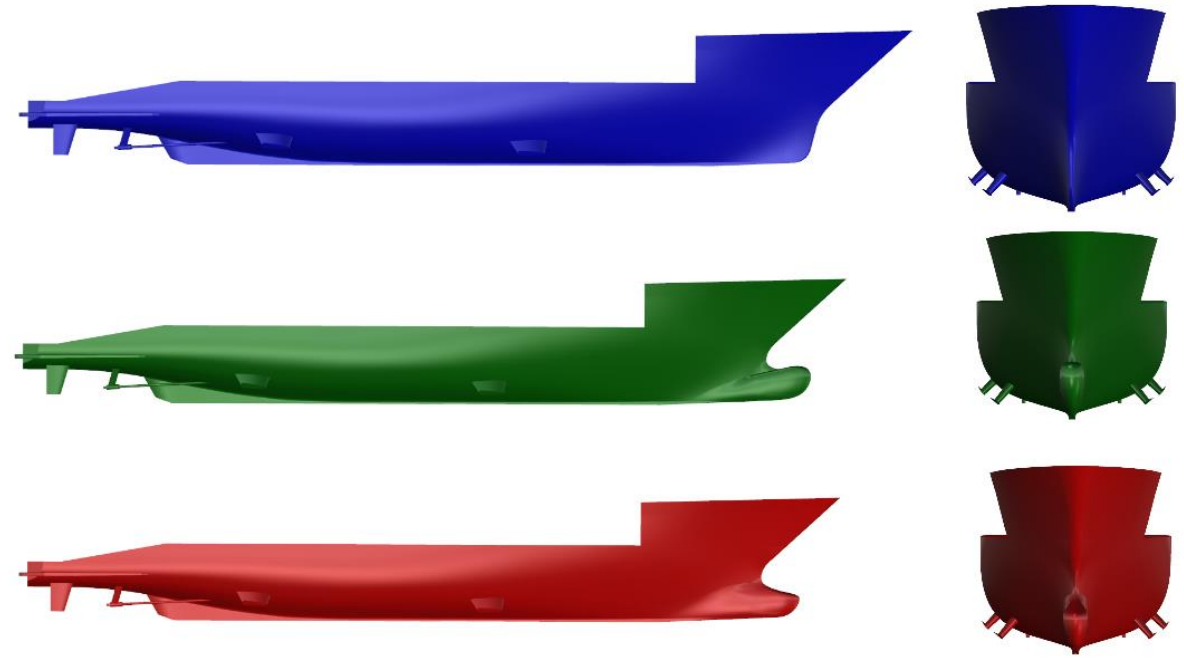

Fig. 1 Model 2508 (top), Model 2508A (middle) and Model 2508B (bottom) [24]

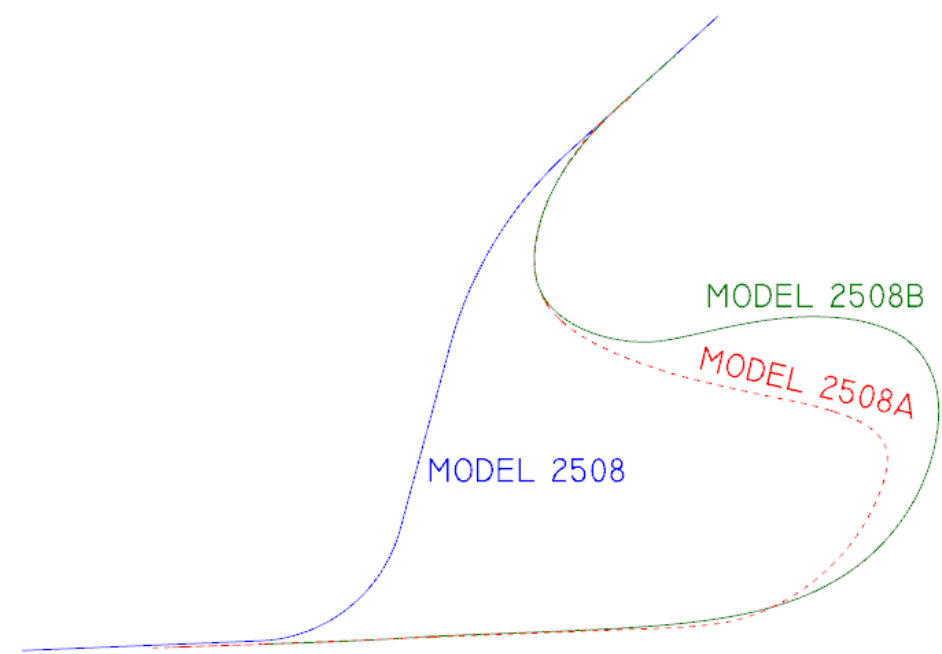

Fig. 2 Bow contour [24]

\section{Methods}

In this section experimental and numerical setup are presented in detail. Experimental towing tank tests are carried out at Vienna model basin (Schiffbautechnische Versuchanstalt). Numerical simulations of resistance tests are carried out using the commercial software package STAR-CCM+ for three models of the yacht utilizing three different turbulence models.

\subsection{Experimental setup}

The experiments were carried out at Vienna model basin, equipped with a towing tank, which is $180 \mathrm{~m}$ long, $10 \mathrm{~m}$ wide and $5 \mathrm{~m}$ deep. The water depth in a towing tank is adjustable using a system of submerged rafts covering complete width of the bottom of the tank. The towing tank carriage is made as enhanced rigidity riveted steel beams and trusses construction. Its maximum towing speed is $7.5 \mathrm{~m} / \mathrm{s}$. It is powered by four, state of the art 
independently operated frequency controlled electric drive motor systems (SIEMENS), each motor driving one towing carriage wheel. The speed control is done by the continuous frequency modulation of the three-phase alternating current electric motors.

Three models of the yacht Model 2508, Model 2508A and Model 2508B are manufactured in in the workshop of the Vienna model basin. The models are manufactured of wood using a lightweight transversal construction approach, and are produced using epoxy wood protection methods applied not only from the outside but from the inside as well, assuring the geometrical stability of the model during its immersion in the water for the experiments. The dimension inspection of the models was conducted using ITTC recommended procedures [28] on the special flat steel control platform. All tested models are equipped with appendages: rudders, shaft brackets, shaft bossings, stabilizing fins that are precisely constructed and installed on the models. The appendages are constructed out of precisely machined brass and mahogany, and are polished prior to the installation.

The models of the yacht are towed by a single axis load cell, namely the unit Z6 produced by Höttinger Baldwin Messtechnik, Figure 3. The load cell is mounted on a towing carriage that is driven to the required model speed. The signal from the load cell is processed by the amplifier system Spider 8 also produced by Höttinger Baldwin Messtechnik. The models are attached to the measuring head of the single axis load cell by a steel wire, which transmits the horizontal force, even though raked propeller shafts and heavy running trim result in the line of action of the thrust not being horizontal. The tow point is in the same horizontal plane as the centre of buoyancy of the model. Parallelogram guides are fitted at bow and stern of the model to prevent unwanted yawing and swaying during the test runs thus allowing the model only to trim and sink. The trim and sinkage during each resistance test run are measured using the ULTRALAB contact free optical sensors produced by General Acoustics. One optical sensor is positioned on the suitable position near the model transom, while the other one is positioned on the suitable position near the model bow. It is important to mention that a certain margin in positioning the optical sensors is available, since with the known length between the optical sensors the calculation of the trim and sinkage at any given position for the models is allowed. Optical sensors are very stable measuring instruments, so the calibration of those instruments is done by the manufacturers at predetermined intervals and not for each resistance test. Prior to each test run a predefined calibration procedure is conducted with the single axis load cell. During the calibration, the connecting steel wire, which is used to tow the model, is detached from the experimental model. A refence zero point is now measured with the single axis load cell connected only to the steel wire. Next, a calibrated weight of $5 \mathrm{~kg}$ is attached on the steel wire and a refence load point is now measured with the single axis load cell. Finally, the calibrated $5 \mathrm{~kg}$ weight is removed, and the previously established refence zero point is measured again with the single axis load cell connected only to the steel wire. The repetition measurement of the reference zero must be stable and precise within minimal deviations. The resistance tests and its evaluation are conducted according to the ITTC procedure [29]. The number of the test points should enable precise polynomic representation of the speed resistance curves connecting the measured points.

Fully developed turbulent flow around the models is assured by the application of the turbulence stimulators on the models i.e., a $10 \mathrm{~mm}$ wide stripe of the carborundum sand is positioned on the longitudinal position of the forward perpendicular over the entire model breadth/height, Figure 4. Since the bulb of the model interacts with the fluid prior to the forward perpendicular it is also necessary to apply an additional $10 \mathrm{~mm}$ wide stripe of the carborundum sand on the entire model bulb breadth/height on a characteristic bulb section, Figure 4. Preparation of the models for the resistance test is carried out according to ITTC recommended procedure [29]. The models are ballasted according to the defined load 
condition as well as the hydrostatic parameters. The weight is set starting with the empty model weight and then the remaining weight is set using the inhouse ballast calibrated weights available in sizes from $0.1 \mathrm{~kg}$ to $20 \mathrm{~kg}$. The proper trim and upright floating positions are verified using an electronic spirit level, where the length of the spirit level must be equal or longer than the model breadth. The precision of the verification is done to $0.01^{\circ}$ accuracy.

The experimental uncertainty is assessed by systematic repetition of the measurements according to the ITTC procedure [30] and it is equal to $0.37 \%$.

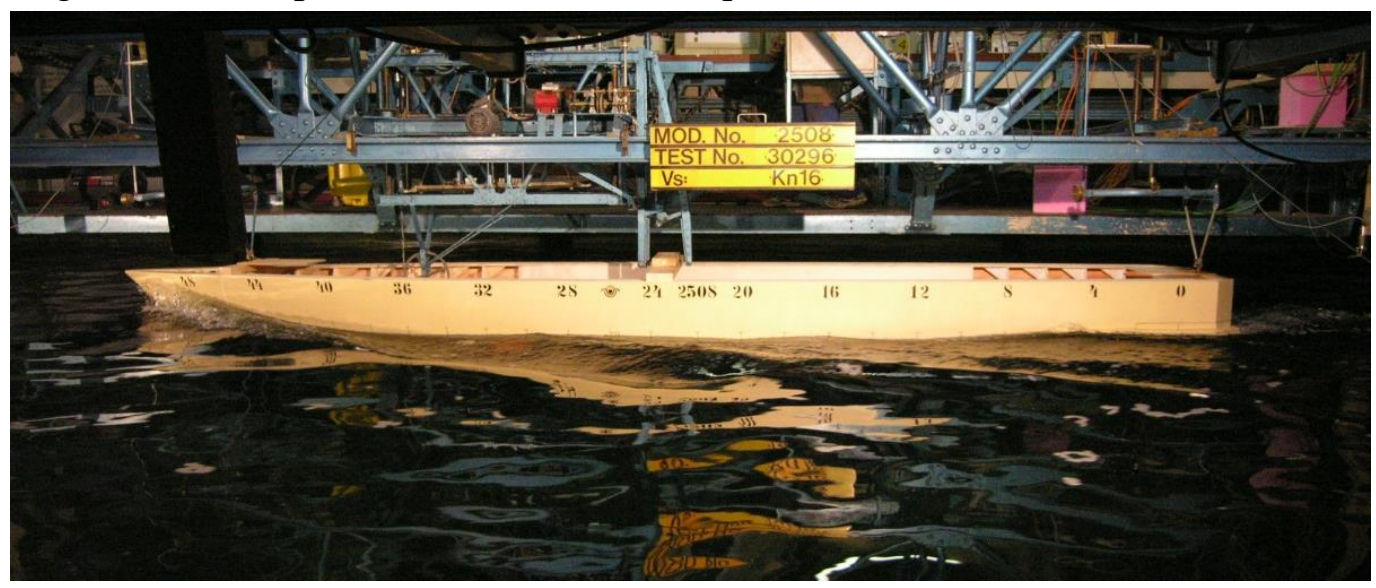

Fig. 3 Model test setup for resistance test [24]

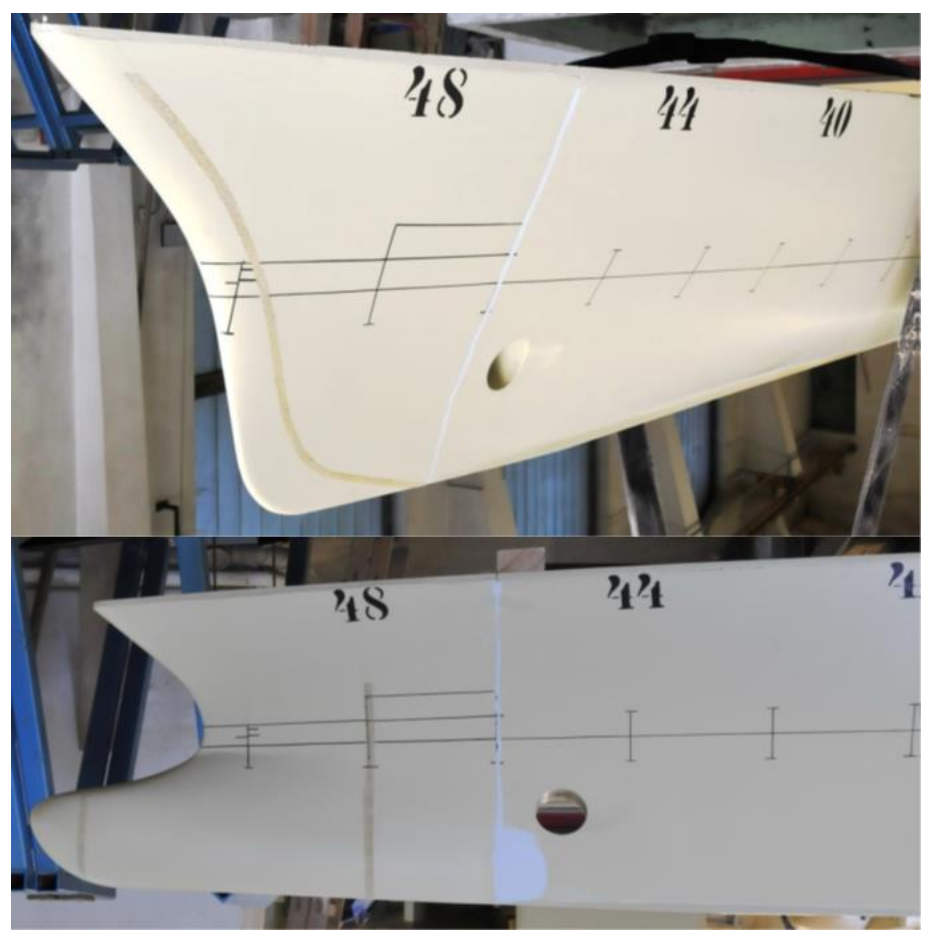

Fig. 4 Turbulence stimulators for Model 2508 (top) and Model 2508A (bottom) [24]

\subsection{Numerical setup}

RANS and averaged continuity equations are used for the description of turbulent flow. Those equations are expressed as follows [31]:

$$
\frac{\partial\left(\rho \bar{u}_{i}\right)}{\partial t}+\frac{\partial}{\partial x_{j}}\left(\rho \bar{u}_{i} \bar{u}_{j}+\rho \overline{u_{i}^{\prime} u_{j}^{\prime}}\right)=-\frac{\partial \bar{p}}{\partial x_{i}}+\frac{\partial \bar{\tau}_{i j}}{\partial x_{j}}
$$




$$
\frac{\partial\left(\rho \bar{u}_{i}\right)}{\partial x_{i}}=0
$$

where $\rho$ is the fluid density, $\bar{u}_{i}$ is the averaged Cartesian components of the velocity vector, $\rho \overline{u_{i}^{\prime} u_{j}^{\prime}}$ is the Reynolds stress tensor (RST), $\bar{p}$ is the mean pressure, and $\bar{\tau}_{i j}$ is the mean viscous stress tensor, defined as:

$$
\bar{\tau}_{i j}=\mu\left(\frac{\partial \bar{u}_{i}}{\partial x_{j}}+\frac{\partial \bar{u}_{j}}{\partial x_{i}}\right)
$$

where $\mu$ is the dynamic viscosity.

Equations (1) and (2) do not form a closed system of equations, therefore a turbulence model is applied. One of the goals of this research is to investigate the influence of different turbulence models on the results of numerical simulations. Therefore, three turbulence models are applied: RKE, SSTKO and RSM. RKE and SSTKO are isotropic eddy-viscosity models, while RSM takes into consideration anisotropy of the Reynolds stresses. More detailed explanation is given in [11]. To track and locate the free surface, the Volume of Fluid (VOF) method is used. The fraction of a fluid in each cell is represented by a function $\alpha_{i}$ and its value defines the volume of fluid in that particular cell. The discretization of the computational domain is carried out by using the unstructured hexahedral mesh, Figure 5. To reduce the computational time, only half of the domain is created i.e., the symmetry boundary condition is applied. The domain boundaries are placed far enough from the model to avoid their influence on the numerical solution [32], Figure 5.

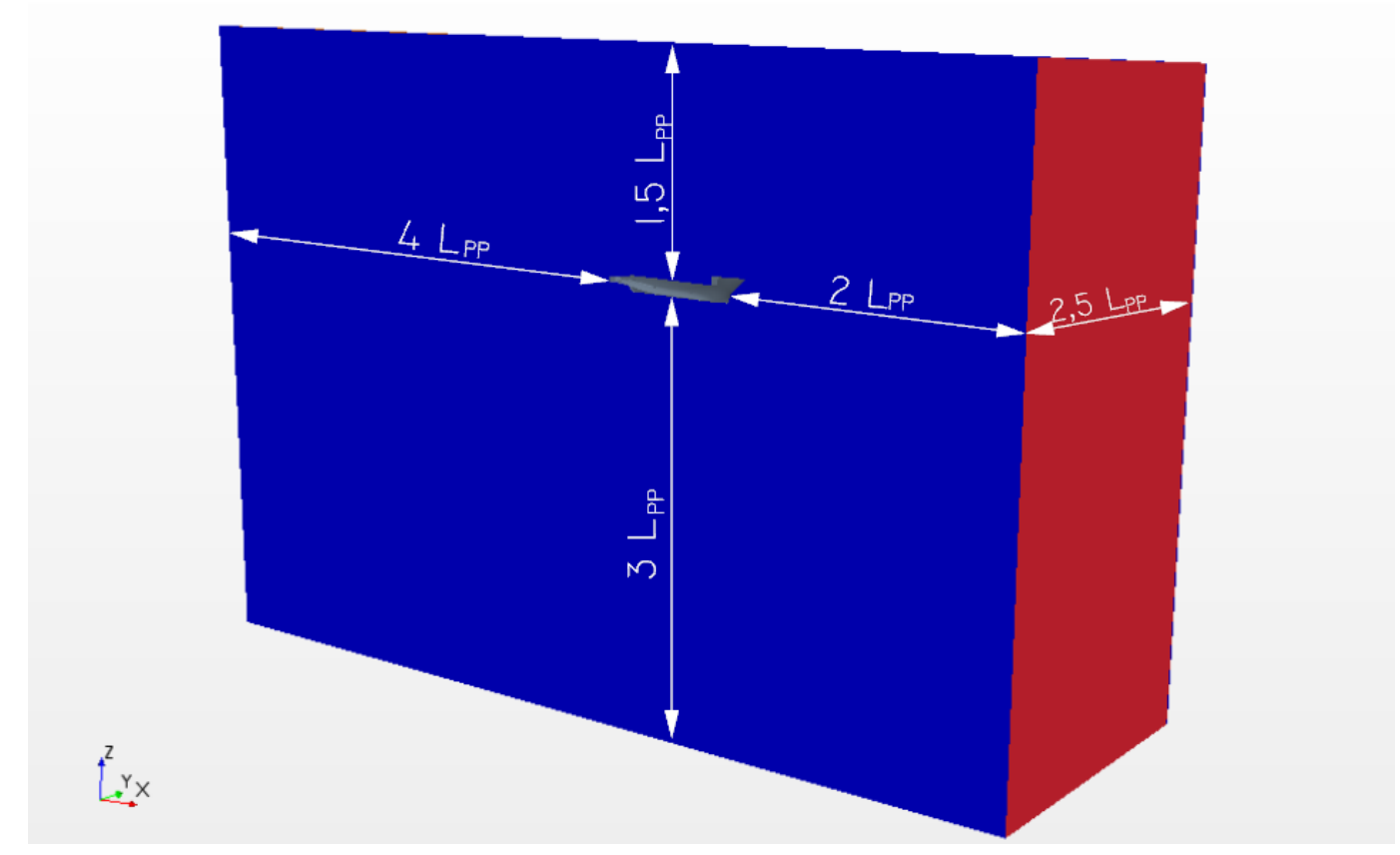

Fig. 5 The computational domain 


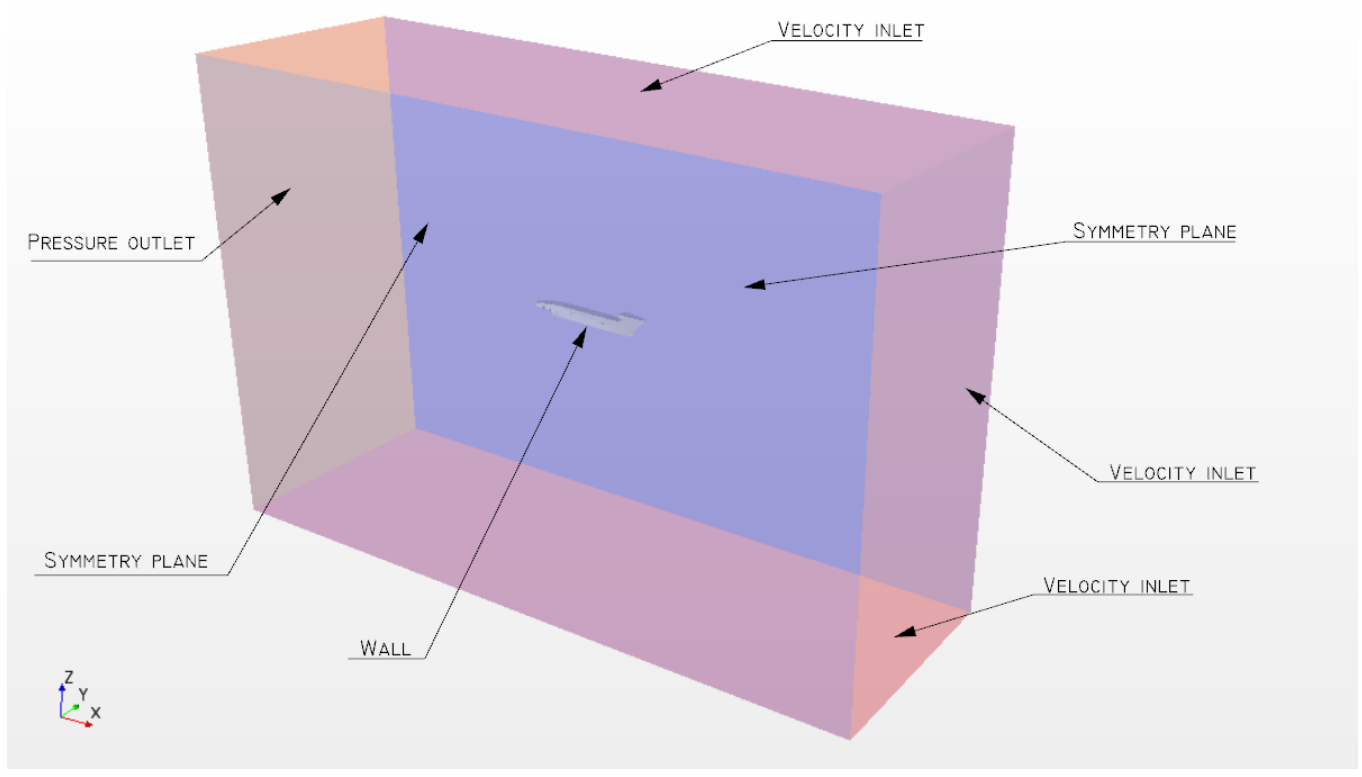

Fig. 6 Boundary conditions

The applied boundary conditions can be seen in Figure 6. The numerical simulation is set up so that the yacht is kept fixed, and the fluid flows at a constant speed. Therefore, at the hull surface no slip wall boundary condition is applied. Top, bottom and the inlet boundaries are defined as a velocity inlet. The outlet boundary is defined as a pressure outlet, and side boundaries are set as symmetry plane. The draught and trim of models of the yacht are predefined, and they are set according to the towing tank experiments [24], as done in [33].

\subsubsection{Verification and validation study}

The verification study must be carried out to assess the simulation numerical uncertainty $\left(U_{S N}\right)$. It is carried out for the resistance test at the speed of $2.524 \mathrm{~m} / \mathrm{s}$ i.e., Froude number of 0.35 , corresponding to the speed of 17 knots in full-scale for two input parameters: grid size and time step. The grid convergence study is done with three mesh sizes using a fine time step, whereas the temporal convergence study is done with three time steps for a fine mesh size. While numerical simulations are carried out for three turbulence models, the verification study is made only for SSTKO turbulence model. $U_{S N}$ is determined using the Grid Convergence Index (GCI) method given in detail in [34], and is obtained as follows:

$$
U_{S N}^{2}=U_{I}^{2}+U_{G}^{2}+U_{T}^{2}
$$

where $U_{I}$ represents the iteration uncertainty, $U_{G}$ represents the grid uncertainty, and $U_{T}$ represents the time step uncertainty. $U_{I}$ is negligible in comparison to $U_{G}$ and $U_{T}$, therefore it is not taken into account in further considerations.

For the purposes of grid verification study three meshes are generated: coarse, medium and fine mesh. It is important to note that the refinement ratio remains roughly the same between coarse and medium mesh, and medium and fine mesh. The refinement ratio is expressed as:

$$
r_{21}=\sqrt[3]{\frac{N_{1}}{N_{2}}}
$$




$$
r_{32}=\sqrt[3]{\frac{N_{2}}{N_{3}}}
$$

where $N$ is the number of cells of each mesh, index 1 represents the fine mesh, index 2 represents the medium mesh and index 3 represents the coarse mesh.

Table 2 The number of cells and their refinement ratios

\begin{tabular}{|c|c|c|c|c|c|}
\hline Model & $N_{3}$ & $N_{2}$ & $N_{1}$ & $r_{32}$ & $r_{21}$ \\
\hline 2508 & $1.09 \mathrm{M}$ & $2.18 \mathrm{M}$ & $4.42 \mathrm{M}$ & 1.25 & 1.26 \\
\hline $2508 \mathrm{~A}$ & $1.17 \mathrm{M}$ & $2.35 \mathrm{M}$ & $4.92 \mathrm{M}$ & 1.26 & 1.27 \\
\hline $2508 \mathrm{~B}$ & $1.13 \mathrm{M}$ & $2.31 \mathrm{M}$ & $4.80 \mathrm{M}$ & 1.27 & 1.27 \\
\hline
\end{tabular}

Different grid sizes and the corresponding refinement ratios are given in Table 2. Concerning the temporal convergence study, following time steps are considered: coarse time step $(0.04 \mathrm{~s})$, medium time step (0.02 s) and fine time step $(0.01 \mathrm{~s})$.

The apparent order of the method is calculated as follows:

$$
p_{a}=\frac{1}{\ln \left(r_{21}\right)}|\ln | \frac{\varepsilon_{32}}{\varepsilon_{21}}\left|+q\left(p_{a}\right)\right|
$$

where $\varepsilon_{32}=\phi_{3}-\phi_{2}$ and $\varepsilon_{21}=\phi_{2}-\phi_{1} . \phi_{i}$ is the solution obtained with the $\mathrm{i}$-th grid or time step. $q\left(p_{a}\right)$ is expressed as:

$$
q\left(p_{a}\right)=\ln \left(\frac{r_{21}^{p_{a}}-s}{r_{32}^{p_{a}}-s}\right)
$$

where $s$ is equal to:

$$
s=\operatorname{sgn}\left(\frac{\varepsilon_{32}}{\varepsilon_{21}}\right)
$$

Furthermore, the extrapolated solution can be obtained as follows:

$$
\phi_{e x t}^{21}=\frac{r_{21}^{p_{a}}-\phi_{2}}{r_{21}^{p_{a}}-1}
$$

Approximated and extrapolated errors are calculated according to:

$$
\begin{aligned}
& e_{a}^{21}=\left|\frac{\phi_{1}-\phi_{2}}{\phi_{1}}\right| \\
& e_{e x t}^{21}=\left|\frac{\phi_{e x t}^{21}-\phi_{1}}{\phi_{e x t}^{21}}\right|
\end{aligned}
$$

Finally, the GCI for fine input parameter is calculated as:

$$
G C I_{\text {fine }}^{21}=\frac{1.25 e_{a}^{21}}{r_{21}^{p_{a}}-1} \cdot 100 \%
$$




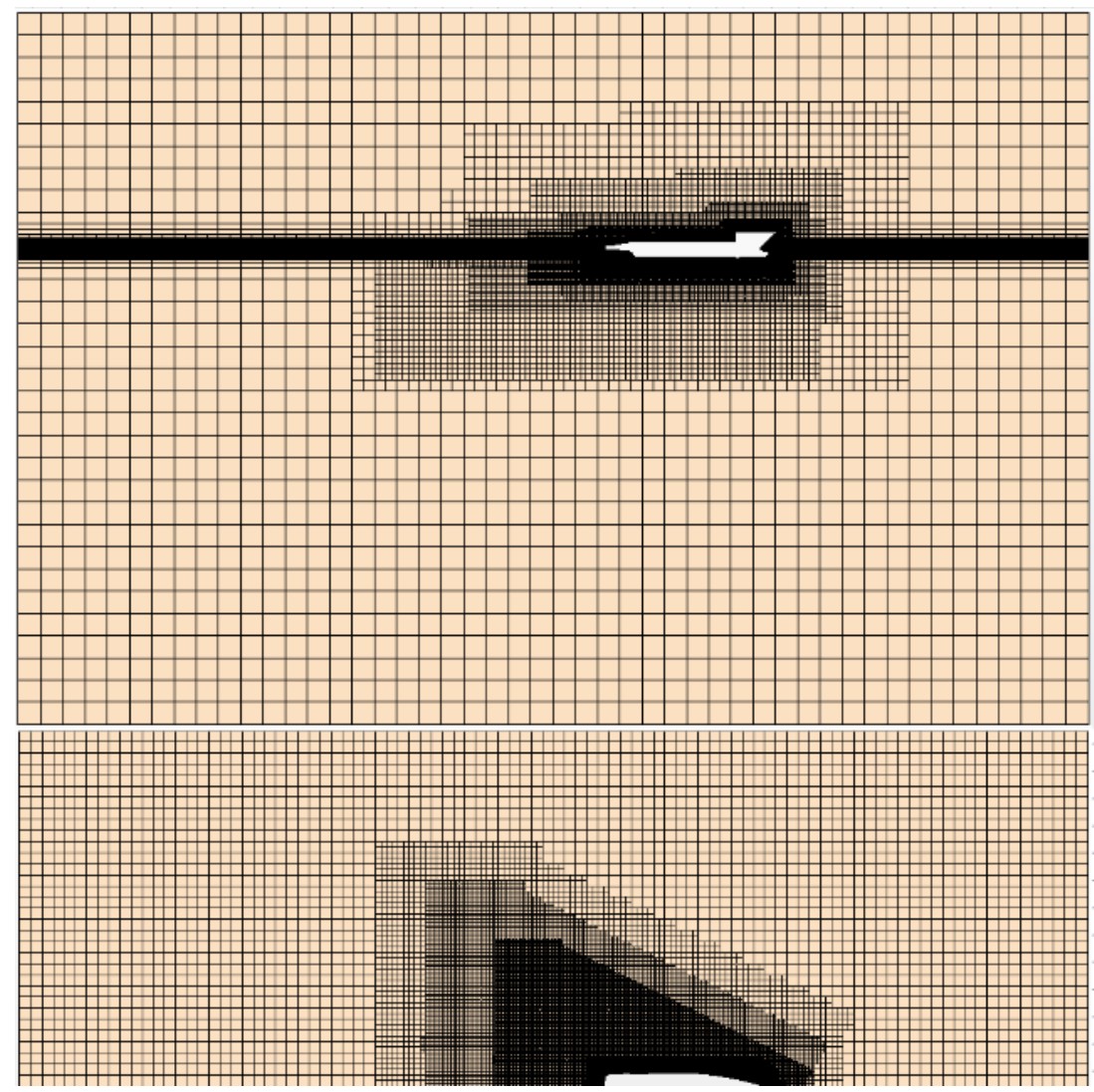

Fig. 7 The generated mesh for Model 2508A, profile view cross section (top) and top view cross section (bottom)

The generated mesh for Model 2508A can be seen in Figure 7, where the refinements around the hull and free surface can be clearly noticed. Special care is given to the near wall mesh treatment by creating a prism layer mesh around the hull and appendages. Since wall functions are used prism layer thickness is set to the value of $y^{+}$between 30 and 100. The obtained $y^{+}$distribution is presented in Figure 8.

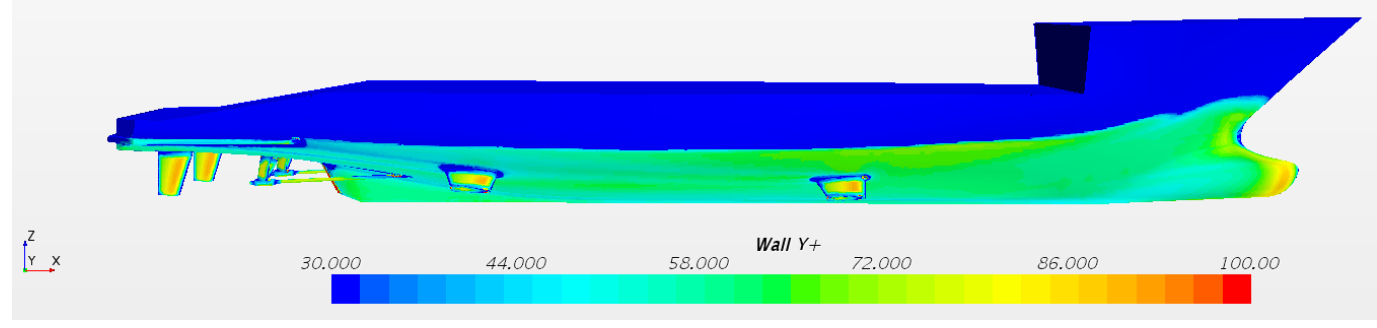

Fig. $8 y^{+}$distribution for model 2508A

Results obtained from numerical simulations are validated with experimental ones. Relative deviation between numerically obtained results $\left(R_{T, C F D}\right)$ and experimental results $\left(R_{T, T T}\right)$ is calculated as follows:

$$
R D=\frac{R_{T, C F D}-R_{T, T T}}{R_{T, T T}} \cdot 100 \%
$$




\section{Results}

In this section, the obtained results of the verification and validation studies are presented. Furthermore, a detailed analysis of the flow around the models of the yacht is carried out to investigate the background of the decrease in the total resistance of the yacht. Thus, the hydrodynamic pressure distribution and wave elevations are shown, and compared for different bow types and turbulence models.

\subsection{Results of the verification study}

Results of the verification study are presented in this subsection. Two input parameters are evaluated, grid size and time step, Tables 3 and 4. It is important to mention that $U_{G}$ and $U_{T}$ are obtained as products of $G C I_{\text {fine }}^{21}$ and $\phi_{e x t}^{21}$.

Table 3 The grid size uncertainty

\begin{tabular}{|c|c|c|c|c|c|c|c|}
\hline Model & $\phi_{3}, \mathrm{~N}$ & $\phi_{2}, \mathrm{~N}$ & $\phi_{1}, \mathrm{~N}$ & $\phi_{\text {ext }}^{21}, \mathrm{~N}$ & $G C I_{\text {fine }}^{21}$ & $G C I_{\text {fine }}^{21}, \%$ & $U_{G}, \mathrm{~N}$ \\
\hline 2508 & 136.32 & 133.13 & 131.80 & 130.90 & 0.0086 & 0.858 & 1.123 \\
\hline $2508 \mathrm{~A}$ & 125.84 & 123.15 & 122.27 & 121.90 & 0.0038 & 0.379 & 0.462 \\
\hline $2508 \mathrm{~B}$ & 128.29 & 125.85 & 125.20 & 124.98 & 0.0022 & 0.223 & 0.279 \\
\hline
\end{tabular}

It can be seen that the obtained numerical uncertainty is relatively low, and it does not exceed $1 \%$ for both grid size and time step. Maximum $\mathrm{GCI}_{\text {fine }}^{21}, \%$ for the grid size uncertainty is equal to $0.858 \%$ and for the time step uncertainty is equal to $0.810 \%$.

Table 4 The time step uncertainty

\begin{tabular}{|c|c|c|c|c|c|c|c|}
\hline Model & $\phi_{3}, \mathrm{~N}$ & $\phi_{2}, \mathrm{~N}$ & $\phi_{1}, \mathrm{~N}$ & $\phi_{\text {ext }}^{21}, \mathrm{~N}$ & $G C I_{\text {fine }}^{21}$ & $G C I_{\text {fine }}^{21}, \%$ & $U_{T}, \mathrm{~N}$ \\
\hline 2508 & 131.91 & 132.06 & 131.80 & 131.4123 & 0.0037 & 0.368 & 0.483 \\
\hline $2508 \mathrm{~A}$ & 122.54 & 122.80 & 122.27 & 121.6994 & 0.0055 & 0.549 & 0.668 \\
\hline $2508 \mathrm{~B}$ & 124.75 & 125.81 & 125.20 & 124.3884 & 0.0081 & 0.810 & 1.008 \\
\hline
\end{tabular}

The obtained simulation numerical uncertainty is calculated according to equation (4), Table 5. It can be seen that the obtained $U_{S N}$ are relatively low, with the highest $U_{S N}$ obtained for Model 2508 equal to $0.933 \%$.

Table 5 The obtained simulation numerical uncertainty

\begin{tabular}{|c|c|c|c|}
\hline & Model 2508 & Model 2508A & Model 2508B \\
\hline$U_{S N}, \%$ & 0.933 & 0.667 & 0.840 \\
\hline
\end{tabular}

\subsection{Resistance tests}

In this subsection the numerically obtained results are presented and validated against the experimental ones. Numerical simulations are carried out at speed equal to $2.524 \mathrm{~m} / \mathrm{s}$ corresponding to the speed of 17 knots in full-scale. Numerical simulations of resistance test are carried out for three models of the yacht using three turbulence models, and the obtained results are presented in Figure 9 and Table 6. The obtained numerical results show satisfactory agreement with the experimentally obtained ones for all investigated turbulence models. As can be from Table 6, the highest $R D$ is equal to $2.08 \%$ and is obtained for Model 2508 and RKE turbulence model. 


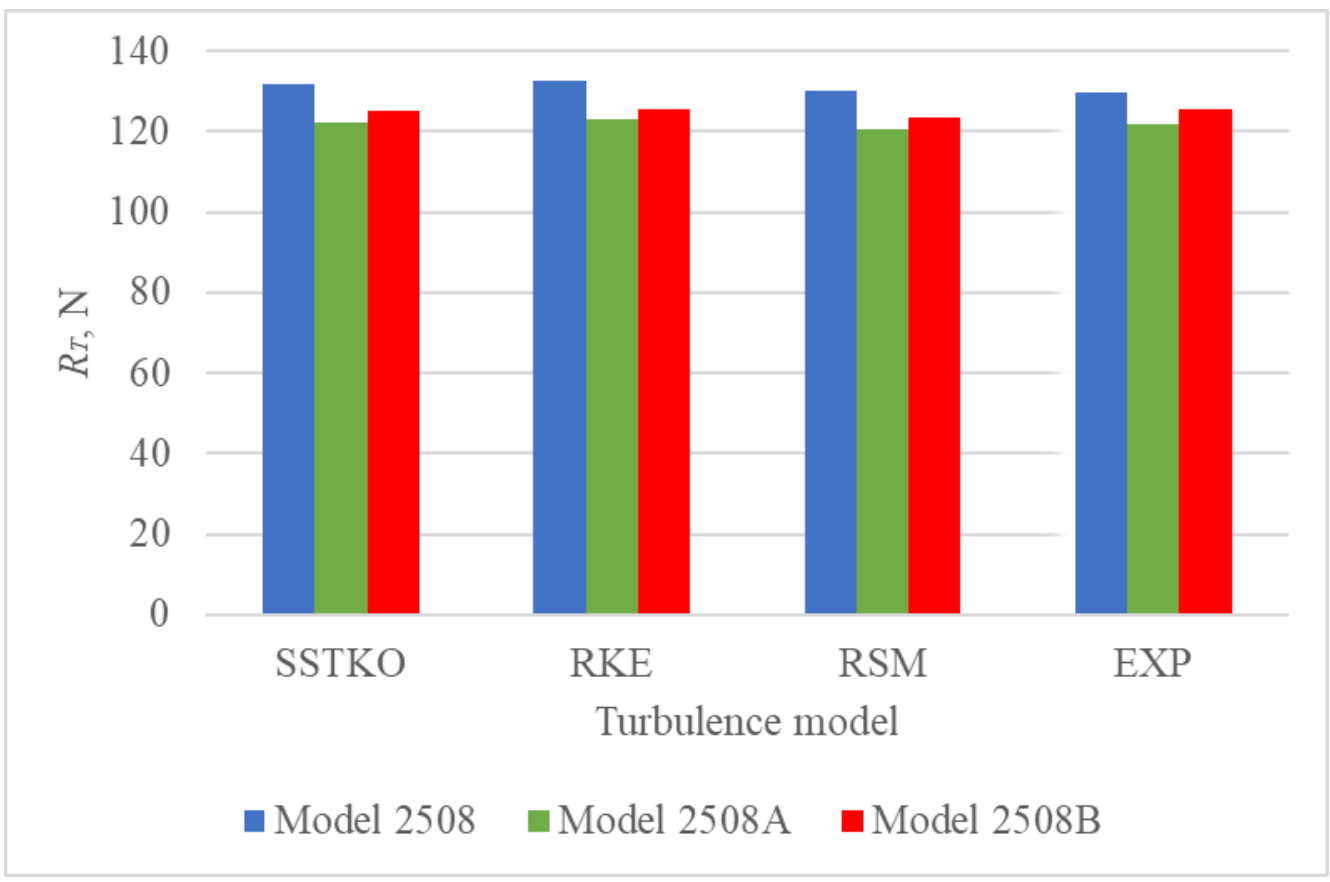

Table 6 The obtained relative deviations

\begin{tabular}{|c|c|c|c|}
\hline & Model 2508 & Model 2508A & Model 2508B \\
\hline$R_{T, \text { EXP }}, \mathrm{N}$ & 129.84 & 121.99 & 125.62 \\
\hline$R_{T, \mathrm{SSTKO}}, \mathrm{N}$ & 131.80 & 122.27 & 125.20 \\
\hline$R D, \%$ & 1.51 & 0.23 & -0.34 \\
\hline$R_{T, \mathrm{RKE}}, \mathrm{N}$ & 132.54 & 122.94 & 125.67 \\
\hline$R D, \%$ & 2.08 & 0.78 & 0.04 \\
\hline$R_{T, \mathrm{RSM}}, \mathrm{N}$ & 129,99 & 120,82 & 123,38 \\
\hline$R D, \%$ & 0.11 & -0.97 & -1.79 \\
\hline
\end{tabular}

To determine the decrease in the total resistance of yacht due to bulbous bow, a comparison of the obtained total resistance is made for Model 2508 with conventional bow type, and Model 2508A and Model 2508B with bulbous bows. According to the experimental results [24] the decrease in total resistance for Model 2508A in comparison with Model 2508 is equal to $6.05 \%$, whereas for Model $2508 \mathrm{~B}$ is equal to $3.25 \%$. The numerically obtained results show slightly higher decreases in total resistance, as can be seen from Table 7 . Thus, it is demonstrated that CFD can be successfully applied within the ship design process.

Table 7 The obtained relative deviations

\begin{tabular}{|c|c|c|c|c|}
\hline & $R_{T, \text { SSTKO }}, \mathrm{N}$ & $R_{T, \text { RKE }}, \mathrm{N}$ & $R_{T, \text { RSM }}, \mathrm{N}$ & $R_{T, \text { EXP }}, \mathrm{N}$ \\
\hline Model 2508 & 131.80 & 132.54 & 129.99 & 129.84 \\
\hline Model 2508A & 122.27 & 122.94 & 120.82 & 121.99 \\
\hline$\Delta R_{T}, \%$ & 7.23 & 7.24 & 7.05 & 6.05 \\
\hline Model 2508B & 125.20 & 125.67 & 123.38 & 125.62 \\
\hline$\Delta R_{T}, \%$ & 5.00 & 5.18 & 5.08 & 3.25 \\
\hline
\end{tabular}




\subsection{Flow analysis around models of the yacht}

In this subsection the analysis of the flow around models of the yacht is presented including hydrodynamic pressure distribution and wave elevations. In addition, the influence of the applied turbulence model on the flow around models of the yacht is assessed.

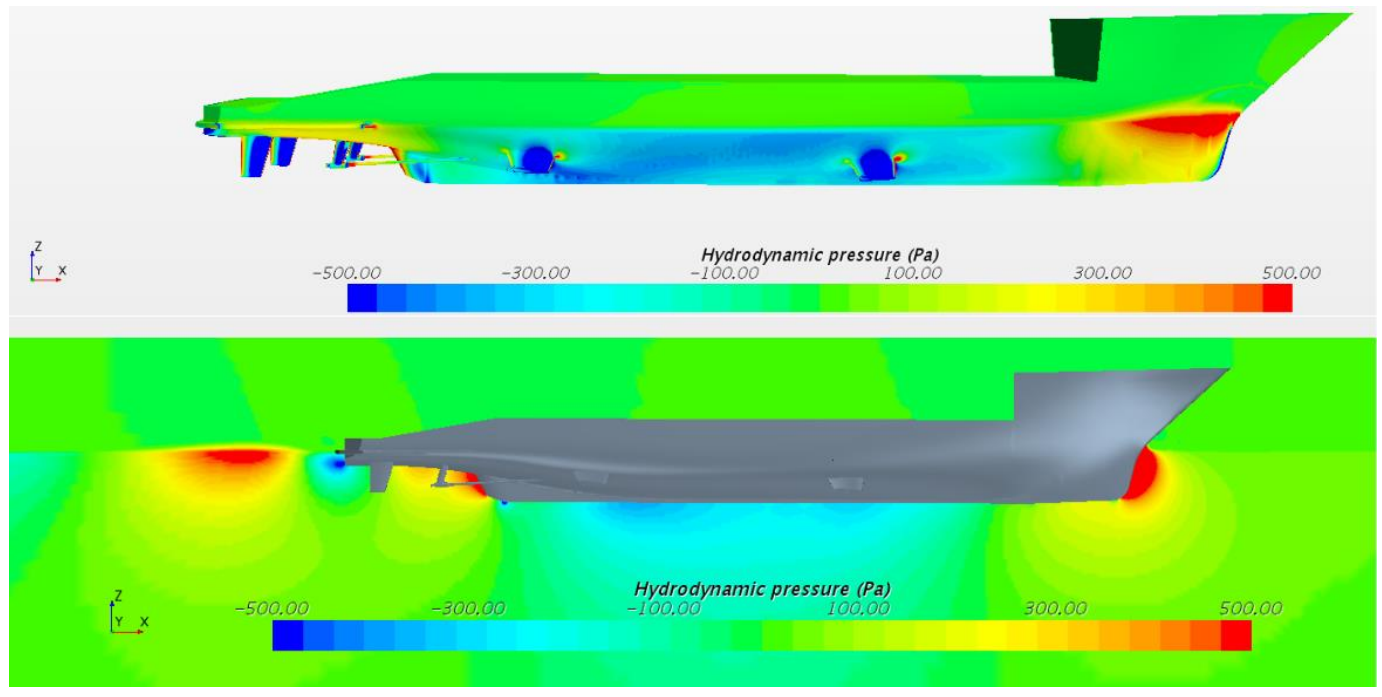

Fig. 10 Hydrodynamic pressure distribution along the hull (top) and on the symmetry plane (bottom) for Model 2508

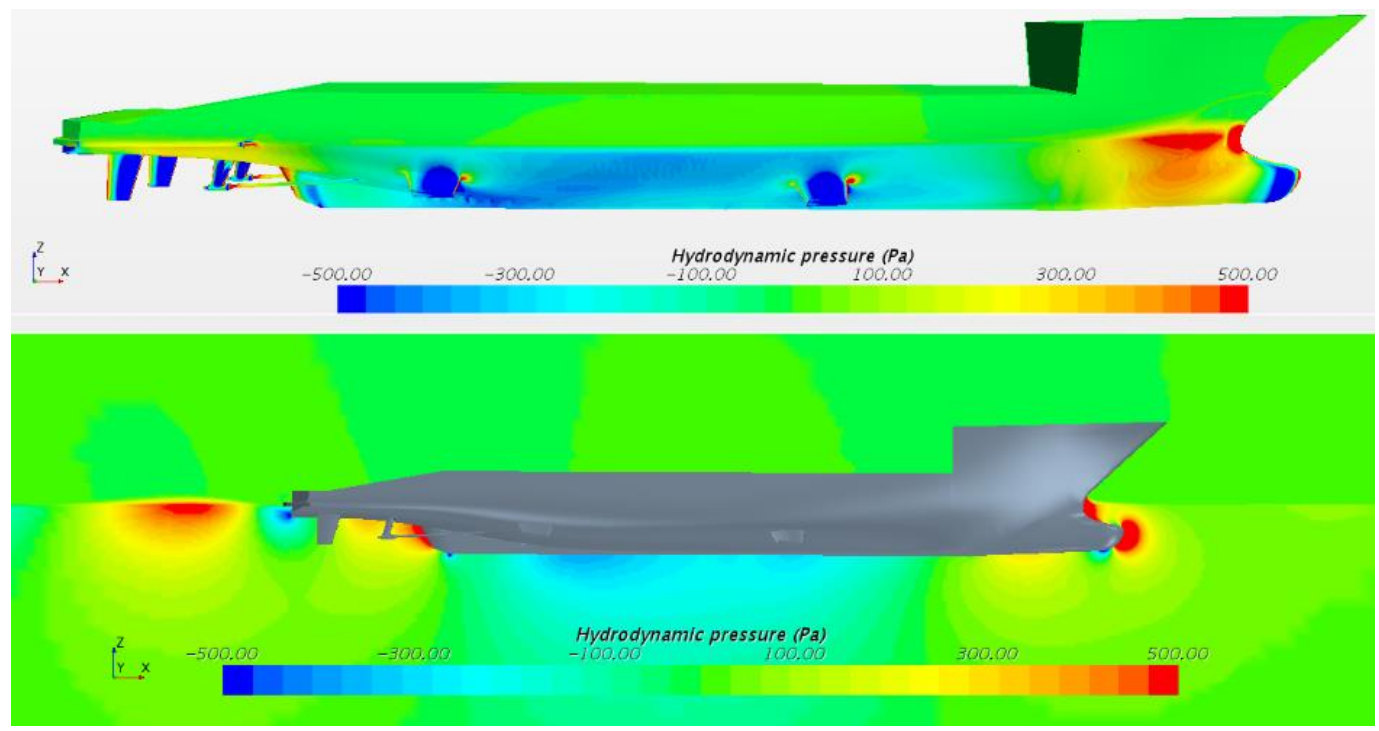

Fig. 11 Hydrodynamic pressure distribution along the hull (top) and on the symmetry plane (bottom) for Model $2508 \mathrm{~A}$

Hydrodynamic pressure distributions along the hull and on the symmetry plane are given in Figures 10.-13. It should be noted that the numerical results presented in Figures 10.13. are obtained with SSTKO turbulence model. From these figures it can be seen that hydrodynamic pressure distribution due to the bulbous bow is affected in the bow region only. A large area of overpressure in the free surface region and underpressure in the bow contour of Model 2508 can be seen in Figures 10 and 13. Significantly smaller area of overpressure and the occurrence of underpressure on bulbous bow can be noticed for Model 2508A, Figures 11 and 13. Model 2508B has similar hydrodynamic pressure distribution as Model 2508A with larger area of overpressure in the bow region, Figures 12 and 13. In addition, due to bulbous bow lower pressure gradient can be seen in the bow region of Model 2508A in comparison to Model 2508, which is in accordance with [17]. Consequently, Model 2508A 
Numerical and experimental assessment of the total resistance of a yacht
Nastia Degiuli, Andrea Farkas, Ivana Martić, Ivan Zeman, Valerio Ruggiero, Vedran Vasiljević

has the lowest total resistance compared to other two models of the yacht. The use of different turbulence models does not alter the pressure distribution, which is in agreement with [11].

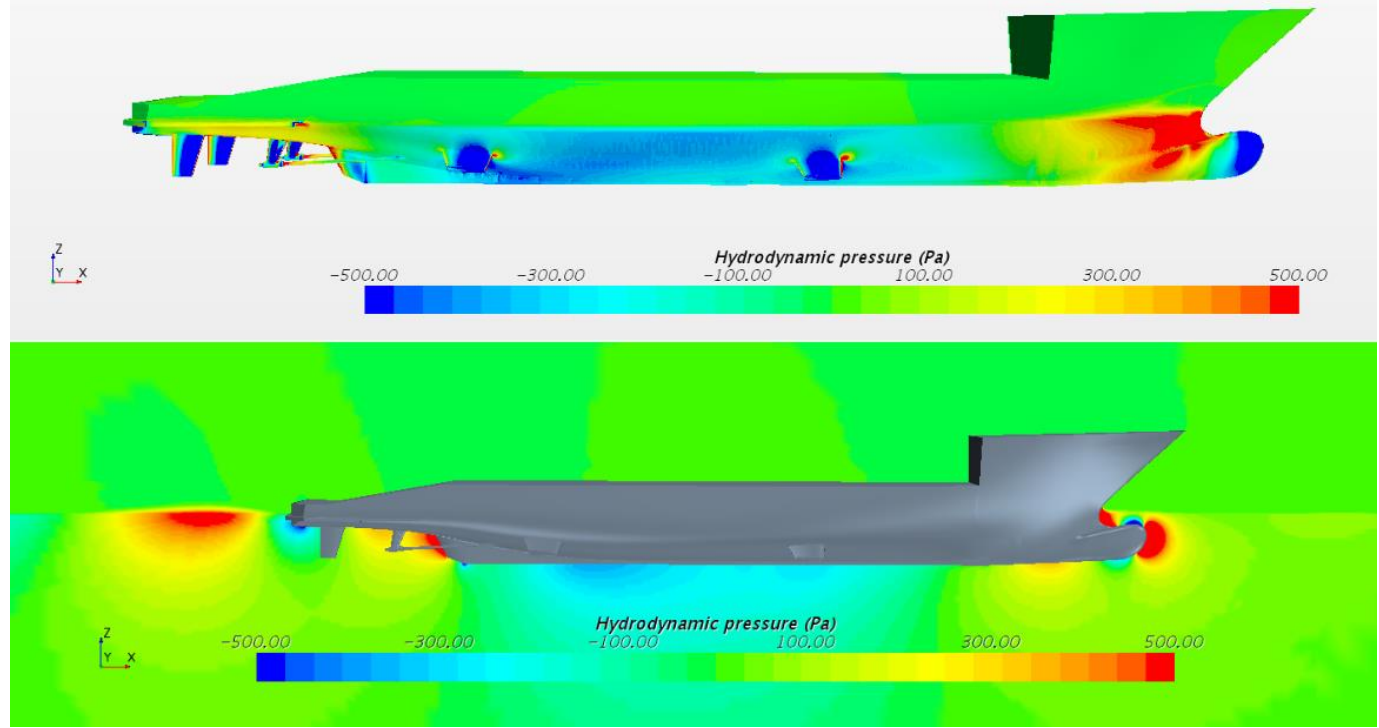

Fig. 12 Hydrodynamic pressure distribution along the hull (top) and on the symmetry plane (bottom) for Model 2508B

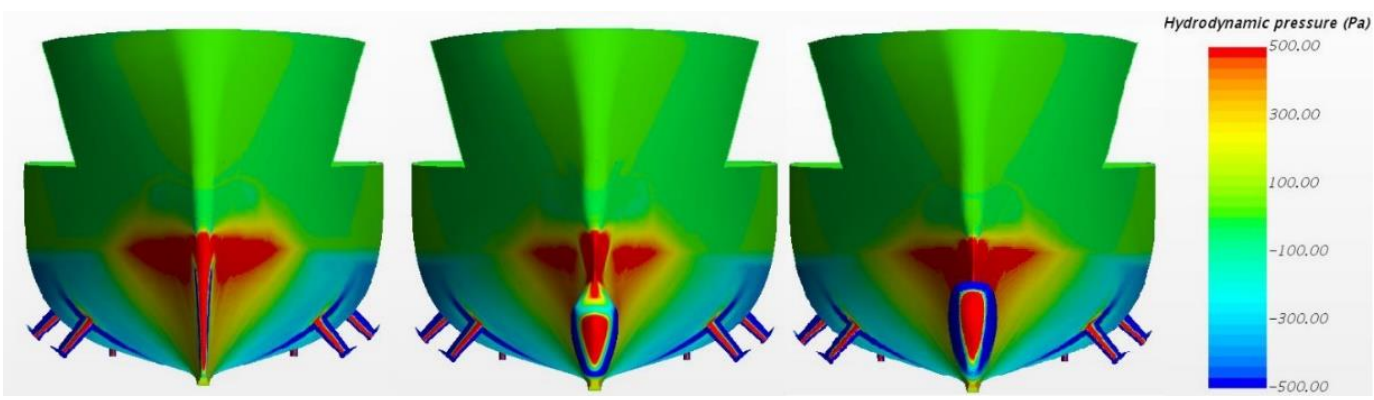

Fig. 13 Hydrodynamic pressure distribution in the bow region for Model 2508 (left), Model 2508A (middle) and Model 2508B (right)

The influence of the bulbous bow on the wave pattern of the models is determined by analysing the longitudinal wave cuts at three different planes: $y=0$ (symmetry plane), $y=0.1 \mathrm{~m}$ and $y=0.2 \mathrm{~m}$, Figures 14 and 15 . The wave elevations in longitudinal planes are obtained using SSTKO turbulence model, and in Figures 14 and 15 are presented for bow region and behind the stern, respectively. Wave elevations are reduced in bow region and behind the stern due to bulbous bow i.e., Model 2508 A and Model 2508 B have lower wave elevations than Model 2508. In addition to, Model $2508 \mathrm{~B}$ has lower wave elevations in the bow region in comparison with Model $2508 \mathrm{~A}$, while in the region behind the stern Model 2508 A has lower wave elevations in comparison with Model 2508 B. Both models with bulbous bow have significantly lower pressure resistance in comparison to model with conventional bow type, which can be explained through the reduction of wave elevations. However, slightly higher frictional resistance is noticed for models with bulbous bow. This can be explained with larger wetted surface area, which is noticed for models with bulbous bow. Model $2508 \mathrm{~A}$ has the lowest value of the total resistance, since its pressure resistance is the lowest and the frictional resistance is lower than for Model 2508 B. Namely, Model 2508 A has lower wetted surface area than Model $2508 \mathrm{~B}$. It should be noted that the results for RKE and RSM turbulence models are similar to the ones obtained using SSTKO turbulence model, which is in accordance with [11]. 


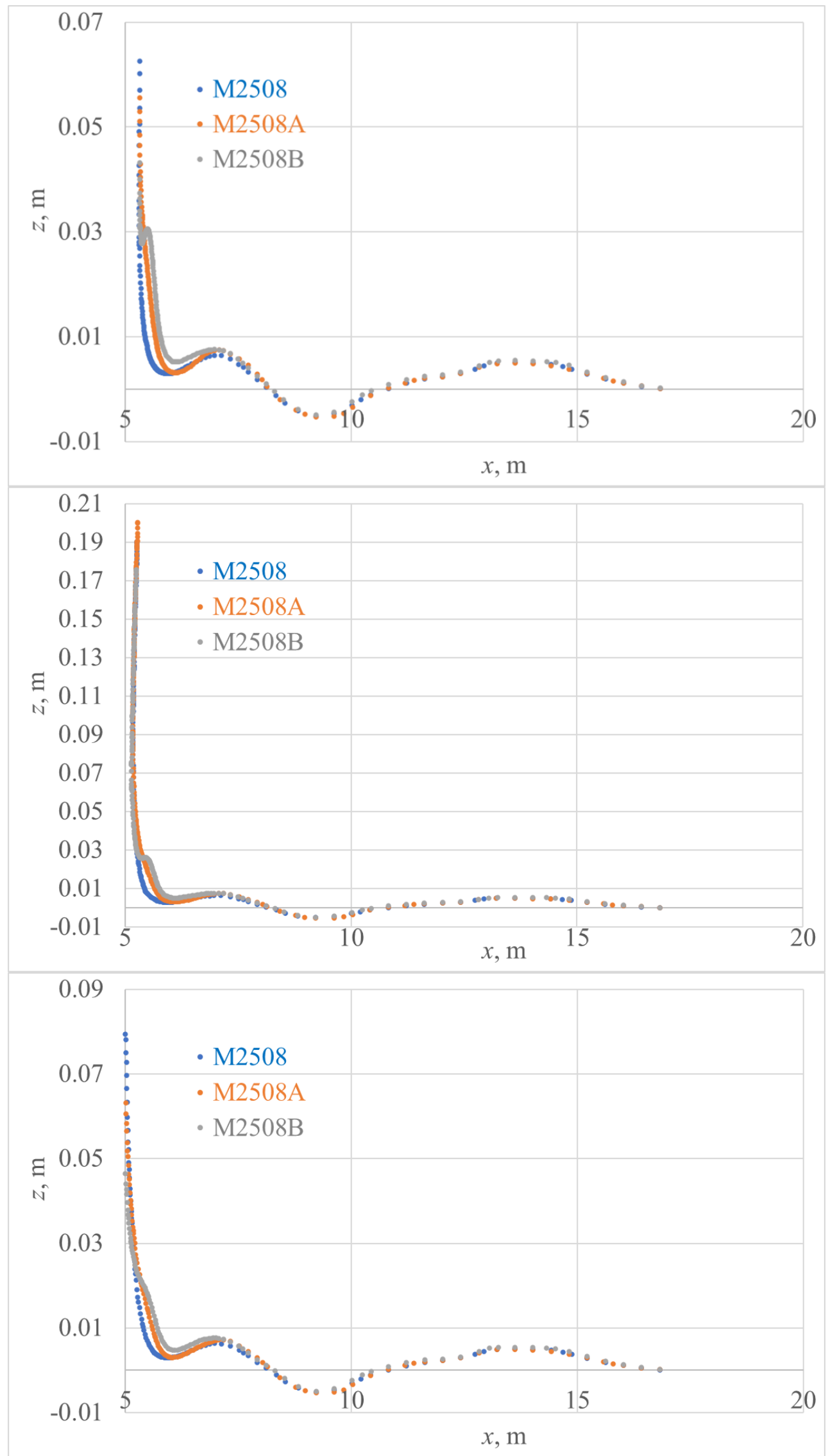

Fig. 14 Longitudinal wave cuts in the bow region: symmetry plane (top), $y=0.1 \mathrm{~m}$ (middle), and $\mathrm{y}=0.2 \mathrm{~m}$ (bottom) 


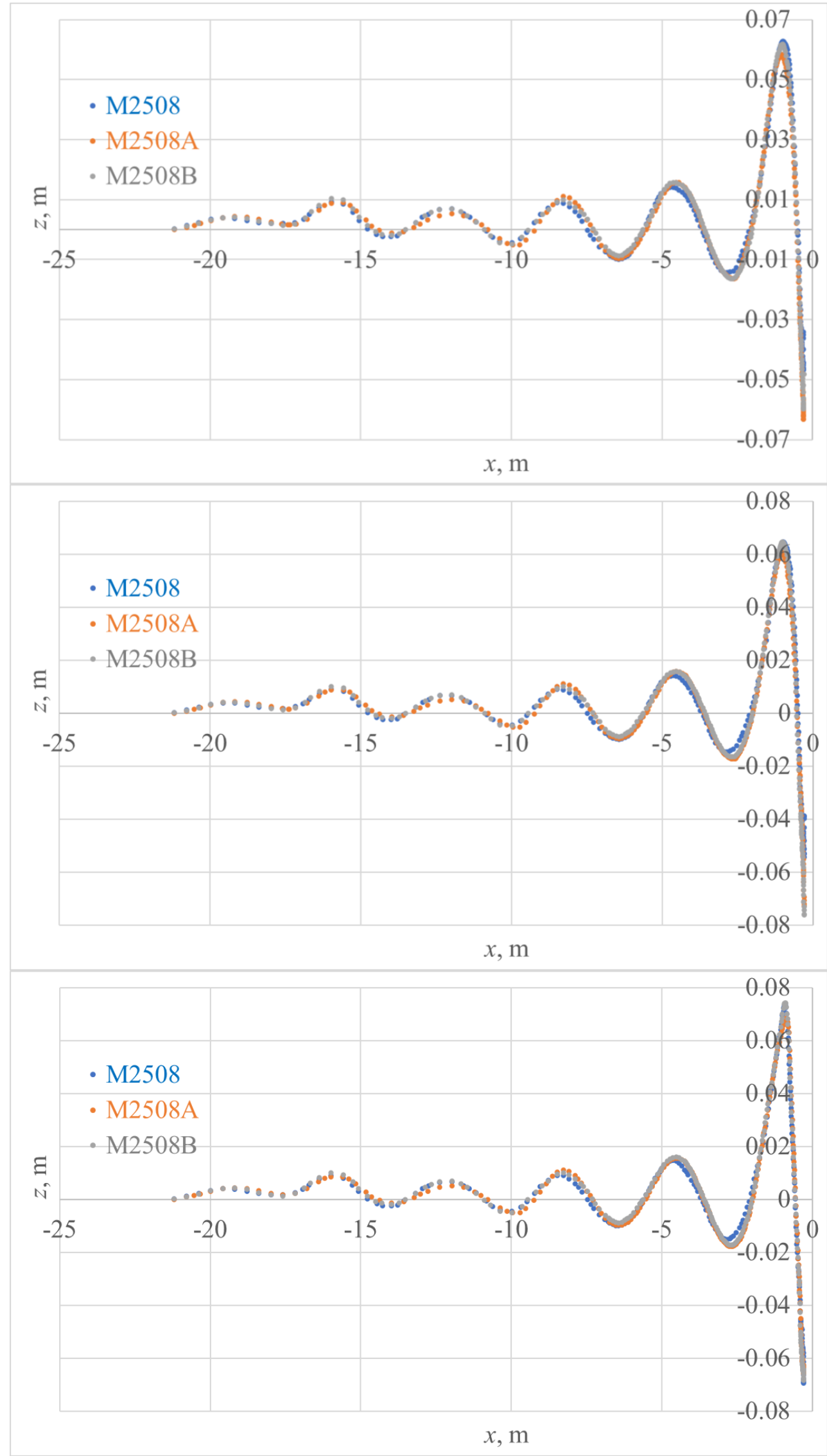

Fig. 15 Longitudinal wave cuts behind the stern: symmetry plane (top), $\mathrm{y}=0.1 \mathrm{~m}$ (middle), and $\mathrm{y}=0.2 \mathrm{~m}$ (bottom) 


\section{Conclusions}

In this paper, numerical simulations of resistance test were carried out in order to investigate the influence of bulbous bow on the total resistance and the flow around three models of the yacht. Also, towing tank experiments were carried out at Schiffbautechnische Versuchsanstalt in Vienna for three models of the yacht. Numerical simulations were carried out within the commercial software package STAR-CCM+ at the speed of $2.542 \mathrm{~m} / \mathrm{s}$ corresponding to the design speed of $17 \mathrm{kn}$ for full-scale yacht. The verification study was performed using three meshes and three different time steps, and it was demonstrated that the obtained simulation numerical uncertainties were relatively low i.e., lower than $1 \%$. Numerical simulations were performed using three turbulence models i.e., RKE, SSTKO and RSM, to investigate their influence on the obtained total resistance and the flow around the models of the yacht. The obtained numerical results were validated against the towing tank results, and satisfactory agreement was obtained with the highest relative deviation equal to $2.08 \%$. It was demonstrated that similar results of the total resistance were obtained regardless of the applied turbulence model. The experimentally obtained decrease in the total resistance for Model 2508A in comparison to Model 2508, which has conventional bow type, is equal to $6.05 \%$, while for Model 2508B is equal to $3.25 \%$. The similar findings were obtained numerically with the decrease in the total resistance for Model 2508A in comparison to Model 2508 around 7\% and Model 2508B around 5\% for all turbulence models. This demonstrates that the CFD can be used within the ship design for the analysis of bow modifications with a goal of decrease in the total resistance. In addition to, CFD enables detailed analysis of the flow around the hull. Thus, by comparison of the hydrodynamic pressure distribution around the hull it was demonstrated that Model 2508A has the smallest area of overpressure region resulting in the decrease in the total resistance. Additionally, longitudinal wave cuts were analysed, and it was shown that both models with bulbous bow have lower wave elevations in comparison to Model 2508 causing the decrease in pressure resistance. It should be noted that the influence of the applied turbulence model on the pressure distribution and wave elevations is negligible. Finally, as the total resistance and wave elevations of a yacht decreased for both analysed bulbous bows, it would be useful to investigate the impact of bulbous bow on the seakeeping characteristics of the yacht, which will form a part of future work.

\section{ACKNOWLEDGEMENT}

This study has been supported by the Croatian Science Foundation under the project IP-202002-8568.

\section{REFERENCES}

[1] Khan, S., Gunpinar, E., Sener, B. GenYacht: An interactive generative design system for computer-aided yacht hull design. Ocean Engineering, 2019; 106462. https://doi.org/10.1016/j.oceaneng.2019.106462

[2] Xing, H., Spence, S., Chen, H. A comprehensive review on countermeasures for CO2 emissions from ships. Renewable \& Sustainable Energy Reviews, 2020; 134: 110222. https://doi.org/10.1016/j.rser.2020.110222

[3] Zhao, D.G., Wang, Y.W., Zhou, G.L. Uncertainty analysis of ship model resistance test in actual seas. Brodogradnja, 2020; 71(4): 81-94. https://doi.org/10.21278/brod71406

[4] Niklas, K., Pruszko, H. Full-scale CFD simulations for the determination of ship resistance as a rational, alternative method to towing tank experiments. Ocean Engineering, 2019; 190: 106435. https://doi.org/10.1016/j.oceaneng.2019.106435

[5] Farkas, A., Degiuli, N., Martić, I. Numerical simulation of viscous flow around a tanker model. Brodogradnja, 2017; 68 (2): 109-125. https://doi.org/10.21278/brod68208 
Numerical and experimental assessment of the total resistance of a yacht
Nastia Degiuli, Andrea Farkas, Ivana Martić, Ivan Zeman, Valerio Ruggiero, Vedran Vasiljević

[6] Ozdemir, Y.H., Cosgun, T., Dogrul, A., Barlas, B. A numerical application to predict the resistance and wave pattern of KRISO container ship. Brodogradnja, 2016; 67 (2): 47-65. https://doi.org/10.21278/brod67204

[7] Bašić, J., Degiuli, N., Dejhalla, R. Total resistance prediction of an intact and damaged tanker with flooded tanks in calm water, Ocean engineering, 2017, 130, 83-91. https://doi.org/10.1016/j.oceaneng.2016.11.034

[8] Martić, I., Degiuli, N., Farkas, A., Bašić, J. Mesh Sensitivity Analysis for the Numerical Simulation of a Damaged Ship Model. Proceedings of the 27th International Ocean and Polar Engineering Conference. June 25-30, 2017, San Francisco, United States.

[9] Pereira, F.S., Eça, L., Vaz, G. Verification and validation exercises for the flow around the KVLCC2 tanker and model and full-scale Reynolds numbers. Ocean Engineering, 2017; 129: 133-148. https://doi.org/10.1016/j.oceaneng.2016.11.005

[10] Farkas, A., Degiuli, N., Martić, I. Assessment of hydrodynamic characteristics of a full-scale ship at different draughts. Ocean $\quad$ Engineering, $2018 ; \quad$ 156: https://doi.org/10.1016/j.oceaneng.2018.03.002

[11] Farkas, A., Degiuli, N., Martić, I., Dejhalla, R. Numerical and experimental assessment of nominal wake for a bulk carrier. Journal of Marine Science and Technology, 2018; 4: 1092-1104. https://doi.org/10.1007/s00773-018-0609-4

[12] $\mathrm{Hu}$, J., Zhang, Y., Wang, P., Qin, F. Numerical and experimental study on resistance of asymmetric catamaran with different layouts. Brodogradnja, 2020; 71(2): 91-110. https://doi.org/10.21278/brod71206

[13] Roshan, F., Dashtimanesh, A., Bilandi, R.N. Hydrodynamic characteristics of tunneled planing hulls in calm water. Brodogradnja, 2020; 71(1): 19-38. https://doi.org/10.21278/brod71102

[14] Yu, J.W., Lee, Y.G. Hull form design for the fore-body of medium-sized passenger ship with gooseneck bulb. International Journal of Naval Architecture and Ocean Engineering, 2017; 9: 577-587. https://doi.org/10.1016/j.ijnaoe.2016.12.001

[15] Huang, F., Chi, Y. Hull form optimization of a cargo ship for reduced drag. Journal of Hydrodynamics, 2016; 28(2): 173-183. https://doi.org/10.1016/S1001-6058(16)60619-4

[16] Khan, S., Gunpinar, E., Dogan, K.M. A novel design framework for generation and parametric modification of yacht hull surfaces. Ocean Engineering, 2017; 136: 243-259. https://doi.org/10.1016/j.oceaneng.2017.03.013

[17] Lee, C.M., Yu, J.W., Choi, J.E., Lee, I. Effect of bow hull forms on the resistance performance in calm water and waves for 66k DWT bulk carrier. International Journal of Naval Architecture and Ocean Engineering, 2019; 11: 723-735. https://doi.org/10.1016/j.ijnaoe.2019.02.007

[18] Lee, J., Park, D.M., Kim, Y. Experimental investigation on the added resistance of modified KVLCC2 hull forms with different bow shapes. Proceedings of the Institution of Mechanical Engineers, Part M: Journal of Engineering for the Maritime Environment, 2016; 231(2): 395-410. https://doi.org/10.1177/1475090216643981

[19] Liu, Z., Liu, W., Chen, Q., Luo, F., Zhai, S. Resistance reduction technology research of high speed ships based on a new type of bow appendage. Ocean Engineering, 2020; 206: 107246. https://doi.org/10.1016/j.oceaneng.2020.107246

[20] Niklas, K., Pruszko, H. Full scale CFD seakeeping simulations for case study ship redesigned from Vshaped bulbous bow to X-bow hull form. Applied Ocean Research, 2019; 89: 188-201. https://doi.org/10.1016/j.apor.2019.05.011

[21] Magionesi, F., Di Mascio, A. Investigation and modelling of the turbulent wall pressure fluctuations on the bulbous bow of a ship. Journal of Fluids and Structures, 2016; 67: 219-240. https://doi.org/10.1016/j.jfluidstructs.2016.09.008

[22] Xie, H., Liu, F., Yu, P., Ren, H. Comparative study on fluid dynamic behavior and slamming loads of two bow-flare sections entering into water. International Journal of Mechanical Sciences, 2020; 166: 105177. https://doi.org/10.1016/j.ijmecsci.2019.105177

[23] Kracht, A. Design of bulbous bows. The Society of Naval Architects and Marine Engineers (SNAME) Transactions, 1978; 86: 197-217.

[24] Schiffbautechnische Versuchanstalt. Report No. 2508/01 - Hydrodynamic Model Tests. Report, Schiffbautechnische Versuchanstalt, Vienna 2011. 
[25] Ruggiero, V. Changes in design approach for large yachts. In: Proceedings of III International Multidisciplinary scientific conference on social sciences \& arts - SGEM 2016, Book 4, Volume II, Vienna, Austria, 6-9 April 2016, pp. 155-164.

[26] Ruggiero, V. New interactive method to determine parameters for large motor yachts stability. International Journal on Interactive Design and Manufacturing, 2019; 13(4): 1557-1564. https://doi.org/10.1007/s12008-019-00605-3

[27] Ruggiero, V. Analysis of changings in mega yacht geometrical characteristics with consequences on resistance and stability. In: Design and construction of super \& mega yachts. Genova, Italy, 14-15 May 2019, The Royal Institution of Naval Architects.

[28] ITTC. Recommended Procedures and Guidelines Model Manufacture Ship Models 7.5-01-01-01. 2017.

[29] ITTC. Recommended Procedures and Guidelines, Testing and Data Analysis Resistance Test 7.5-02-0201. 2011.

[30] ITTC. Recommended Procedures and Guidelines, General Guideline for Uncertainty Analysis in Resistance Tests 7.5-02-02-02. 2014.

[31] Ferziger, J.H., Perić, M., Computational Methods for Fluid Dynamics. $3^{\text {rd }}$ edition. Berlin: Springer Science \& Business Media, 2002. https://doi.org/10.1007/978-3-642-56026-2

[32] ITTC. Recommended Procedures and Guidelines, Practical Guidelines for Ship CFD Applications 7.5-0302-03. 2011.

[33] Zaghi, S., Broglia, R., Di Mascio, A. Analysis of the interference effects for high-speed catamarans by model tests and numerical simulations. Ocean Engineering, 2011; 38(17-18): 2110-2122. https://doi.org/10.1016/j.oceaneng.2011.09.037

[34] Farkas, A., Degiuli, N., Martić, I. Impact of biofilm on the resistance characteristics and nominal wake, Proceedings of the Institution of Mechanical Engineers, Part M: Journal of Engineering for the Maritime Environment, 2019; 234(1): 59-75. https://doi.org/10.1177/1475090219862897

\footnotetext{
Submitted: $\quad$ 26.07.2021. Nastia Degiuli, nastia.degiuli@fsb.hr Andrea Farkas

Accepted: $\quad$ 15.09.2021. Ivana Martić Ivan Zeman University of Zagreb, Faculty of Mechanical Engineering and Naval Architecture Valerio Ruggiero University of Messina, Department of Engineering Vedran Vasiljević Vienna model basin LTD
} 